\title{
The epidemiological situation of leprosy in India
}

\section{CHRISTIAN}

Schieffelin Leprosy Research and Training Centre, Karigiri, India

The origins of leprosy are shrouded in the mists of antiquity. Its early spread is also largely a matter of surmise. The disease however has been present in the Indian sub-continent for several centuries. Information regarding its extent and distribution has been very meagre until recent years. The 1931 Census gave the number of leprosy cases as 150,000. Since then anti-leprosy work has been intensified, especially in the post independence years after 1948 and more particularly after the National Leprosy Control Programme was launched by the Government of India in 1955. The estimated number of cases has consequently been rising in successive decennial population counts as shown in Table 1 .

Table 1. Census population and estimated leprosy cases.

\begin{tabular}{lcc}
\hline $\begin{array}{l}\text { Year of } \\
\text { Census }\end{array}$ & $\begin{array}{c}\text { Population } \\
\text { in million }\end{array}$ & $\begin{array}{c}\text { Estimated Number of } \\
\text { Leprosy Cases } \\
\text { in millions }\end{array}$ \\
\hline 1941 & 319 & 1.5 \\
1951 & 361 & 2 \\
1961 & 439 & 2.5 \\
1971 & 547 & 3.2 \\
1981 & 684 & 4 \\
\hline
\end{tabular}

The main factors responsible for this progressive increase were as follows (1):

1) Rapid increase in the population.

2) Increased activity in the case finding component of the control programme.

3) Increased Voluntary Reporting due to community awareness regarding the disease.

These explanations have been put forward to assert that the increase 
in the number of leprosy cases is in proportion to the increase in population and is therefore not an absolute or actual increase. While this may no doubt be true, it is obvious that the revised strategy for the containment of leprosy launched twenty-five years ago has failed to achieve interruption of disease transmission in the community.

\section{Magnitude of the problem}

The estimated number of patients in the country is 4 million, based on the 1981 Census population of 683.9 million. The Lepromatous Rate ranges between 10 to 25\% in different areas and the Deformity Rate is approximately 20\%. About 400 million people live in hyperendemic and moderately endemic areas where active transmission is continuing and are therefore exposed to the risk of infection. Seventy-two districts in the country have been identified as hyper-endemic for leprosy with prevalence rates above 5 per 1000. The magnitude of the problem is therefore vast and the consequent need to achieve control gains greater urgency in the context of attaining our social objective of Health for All by 2000 A.D.

\section{Distribution of leprosy}

Though the disease is found throughout the country it is not equally distributed in this sub-continent. Variations in the prevalence of the disease and its geographical distribution can be seen in Fig. 1 (1). However, a definite pattern can be established demarcating high, moderate and low endemic areas. There may be wide variations in prevalence even in a low endemic area with pockets of high endemicity. The reasons for this tendency to focalization is still not clear and awaits elucidation through detailed epidemiological studies.

The areas of high prevalence, 10 per 1000 or more, are found mainly in the South Eastern parts of the country, though there may be foci of high prevalence in Central, Western and North Eastern India. This belt of high prevalence includes Tamil Nadu, Andhra Pradesh, Orissa, Pondicherry and the Lakshadweep Islands.

The areas of moderate prevalence, 1 to 10 per 1000 , are found mostly in the Central and Western parts of the country and the Himalayan foot hills. These areas include Assam, Bihar, Himachal Pradesh, parts of Jammu and Kashmir, Kerala, Madhya Pradesh, Maharashtra, Karnataka and the Eastern parts of Uttar Pradesh.

The areas of low prevalence, below 1 per 1000, are found mostly in the North Western parts of the country. These areas include the plains of Punjab, Haryana, the Western parts of Uttar Pradesh, Gujarat and Rajasthan. 
Prevalence patterns in hyper-endemic areas

Tamil Nadu is hyper-endemic for leprosy with an overall prevalence rate of 19 per 1000. Out of 15 districts in the state (excluding Madras City), 14 have a prevalence rate of 10 or more per 1000 . It is interesting to examine the conditions prevailing in Niligris District, where leprosy is a negligible public health problem. Niligris is in the hill ranges of the Western Ghats at an elevation of 5000 to 8000 feet above sea level. The area is sparsely populated with a density of 246 per sq. km. The literacy rate at $55.75 \%$ is also one of the highest in the State. In Dharmapuri District the prevalence of leprosy is 20 per 1000 though the density of population is only 207 per sq. km. However this is one of the most backward districts, drought prone throughout the year and inhabited largely by marginal farmers. The literacy rate is also the lowest at $28.62 \%$. In contrast in Kanyakumari where the prevalence rate is only 10 per 1000, the density of the population is 843 per sq. km. However the literacy rate in this district is the highest in the state at $62.06 \%$. Except in the Niligris, in all high frequency districts in this State, temperatures and relative humidity are high throughout the year. A discussion of the validity of these statistics is beyond the scope of this paper. Further observations are necessary to study prevalence rates of the disease in relation to various parameters like density of population, literacy rates, socio-economic conditions and other environmental factors. Literacy rates in particular are sensitive parameters of the socio-economic status and health consciousness of the community and also of acceptable levels of personal hygiene, particularly in developing countries.

Andhra Pradesh is another state bordering Tamil Nadu on the East Coast of India which is hyper-endemic for leprosy. The average prevalence rate for this state is 14.5 per 1000 . In three districts of this state the findings of an Epidemiological Survey in 1944 (2) are contrasted with the situation prevailing in 1981 in Table 2 .

Table 2. Comparison of Prevalence Rates in 1944 and 1981.

\begin{tabular}{|c|c|c|c|c|}
\hline DISTRICT & $\begin{array}{c}\text { P.R. Per } \\
1000 \\
(1944)\end{array}$ & $\begin{array}{c}\text { P.R. Per } \\
1000 \\
(1981)\end{array}$ & $\begin{array}{c}\text { L. Rate } \\
1944 \\
8\end{array}$ & $\begin{array}{c}\text { L. Rate } \\
1981 \\
8\end{array}$ \\
\hline Warangal & 3.0 & 16.2 & 47 & 12 \\
\hline Karimnagar & 2.4 & 10.8 & 23.5 & 11 \\
\hline Adilabad & 3.0 & 10.5 & 28.1 & 13 \\
\hline
\end{tabular}


While the increase in prevalence rates may no doubt be attributed in part to more sensitive methods of case detection, the fourfold rise suggests that there is an absolute increase, which is due to continuing active transmission and extension of the disease in the district. It is interesting to note that with the increase in prevalence the lepromatous rate has shown a downward trend.

These two States. of Tamil Nadu and Andhra Pradesh which account for only $14.9 \%$ of the total population of this country have nearly $50 \%$ of the estimated case load for the entire sub-continent. The epidemiological significance of this preponderance of cases is still not clear. In these hyper-endemic states the epidemiological pattern of the disease can be briefly summarised as follows:

1) The Lepromatous Rate is low varying between 8 to $15 \%$.

2) The Child Rate tends to be high varying between 20 to $30 \%$.

3) There is a sex differential in favour of males which is more evident among adults.

Prevalence pattern in hypo-endemic areas

In low frequency areas however the disease appears to have a different pattern. In Rajasthan in North-West India, leprosy has always been considered a negligible public health problem. Recently, however, pockets of high prevalence have been identified in this state. The lepromatous rate is high, varying between 30 to 50\% (3). While this could be due to a genetic factor since the people are predominantly of Aryan stock, as compared to the Dravidian origins of the inhabitants of the southern states, it can also be explained by under-diagnosis of early indeterminate and tuberculoid cases. Despite the high lepromatous rate however the child prevalence is low, in contradistinction to the prevailing situation in the hyperendemic southern states of India. These findings seem to suggest that leprosy has comparatively recently been introduced to NorthWestern India (4). They do not however conform to the characteristic changes in the pattern of leprosy which occurs when a previously unexposed population acquires experience with leprosy as occurred in Nauru (5) and New Guinea (6). The introduction and spread of leprosy in Rajasthan may be attributed to the following factors:

1) Recruitment to the Army of local inhabitants and service for long spells in hyper-endemic states throughout the country.

2) Business ventures by people of this region to hyper-endemic areas in the country.

3) Influx of labourers from Bihar and Eastern Uttar Pradesh which are known to have a high prevalence of leprosy.

Epidemiological differences between hyper-endemic and hypo-endemic areas

The pattern of leprosy in these two situations can therefore be 
summarized as follows:

Hyper-endemic Areas

1) The Lepromatous Rate is low being 8 to $15 \%$.

2) The child rate is high.

3) There is a sex differential, in favour of males, which is more manifest among adult lepromatous patients.

4 ) The importance of household infection is less significant.

5) Association of multiple case families is less frequent.
Hypo-endemic Areas

1) The Lepromatous Rate is high being 30 to $45 \%$.

2) The child rate is low.

3) There is a high proportion of cases among women without the usual sex differential.

4) The importance of household infection is more significant, with low population density, scattered villages and a rugged landscape.

5) Association of multiple case families is more frequent.

These observations need to be confirmed by detailed epidemiological studies.

Variations in clinical manifestations

It would be pertinent to draw attention to diffuse lepromatous leprosy which is the common form of lepromatous leprosy diagnosed among the dark skinned races of Dravidian origin who inhabit the alluvial plains of South India. Minimal infiltration is a characteristic of this form of leprosy. There is often widespread involvement with little or no suggestion of inflltration, except perhaps a peculiar indefinite mottling, due to slight erythema obscured by the pigment in the skin. These asymptomatic lepromatous patients are often difficult to diagnose unless skin smears are taken when there is a high degree of suspicion of the disease. The epidemiological significance of this form of leprosy is therefore of the utmost importance since its transmission potential among the community is high. In tuberculoid leprosy, marked cutaneous nerve involvement and nerve abscesses are also manifestations which are more frequently seen in India, particularly in.the Northern States, than in other countries of the South East Asia Region.

\section{Urban shift}

There has been a progressive shift in the pattern of the disease to urban areas. In the early part of this century leprosy in India was primarily considered a rural disease. Today with increasing industrialization and the rapidly changing social milieu, there has been an extensive migration to urban areas with the proliferation of slums and shanty towns. Recent data from Madras, Visahkapatnam and Bombay 
where the German Leprosy Relief Association is undertaking comprehensive urban leprosy work can be seen in Table 3 .

Table 3. Prevalence of Leprosy in Urban Areas.

\begin{tabular}{cccc}
\hline Parameters & Madras & Visahkapatnam & Bombay \\
\hline $\begin{array}{l}\text { Population covered } \\
\text { Cases under treatment } \\
\text { May 1981 }\end{array}$ & $24,600,000$ & 596,000 & 773,000 \\
$\begin{array}{l}\text { Prevalence per } 1000 \\
\text { Preva }\end{array}$ & 15.2 & 5,630 & 11,754 \\
\hline
\end{tabular}

Leprosy in urban areas is therefore emerging as a special and complex public health problem particularly in the metropolitan cities of India.

Time trends in the prevalence of leprosy

In areas where leprosy control activities have been in progress for more than 20 years there is a change in the profile of new patients registered annually which can be summarized as follows:

1) The sequential annual detection of new cases shows a down ward trend after 5 years of commencement of control work.

2) Lepromatous leprosy shows a steady linear decrease throughout the entire period, while Tuberculoid and Indeterminate cases tend to stabilize reaching a plateau phase after a 10 year period.

3) There is also a definite shift to the younger age groups with early Indeterminate and single Tuberculoid lesions predominating.

4) The Deformity Index shows a definite downward trend.

5) Emergence of Dapsone resistance among Lepromatous patients commences after about 5 to 10 years of control work.

$\underline{\text { Social aspects }}$

The stigma and ostracism against leprosy still continues despite intensive health education. However, this tends to be less in the hyper-endemic Southern States in India where leprosy is a more common disease. It is also less intense in rural areas than in urban areas and is directly proportional to the literacy rate and the educational status of the community. 
Dapsone resistance

Secondary dapsone resistance is emerging as a major problem in areas where leprosy control work has been operational since the National Leprosy Control Programme was launched in 1955. A study of the prevalence of secondary dapsone resistance in Gudiyatham Taluk of Tamil Nadu is now under progress at Schieffelin Leprosy Research and Training Centre (7). Recent analysis of the data obtained indicates that Dapsone resistance is more widely prevalent than assumed earlier. A systematic follow-up of 1,431 patient in the BB-LL spectrum has been undertaken since 1978-1979 and 85 patients have now been proved as Dapsone resistant after mouse footpad studies. This gives a prevalence figure of $5.93 \%$.

Similar studies in other regions of the country have also confirmed the widespread emergence of secondary Dapsone resistance.

\section{Conclusion}

Leprosy today continues to remain an important public health problem in the Indian sub-continent. Lack of accurate knowledge regarding its epidemiology and limited resources to investigate and combat the disease are some of the factors hindering progress in our efforts at containment of disease transmission. The geographical distribution of the disease shows great variation in pattern with a tendency to focalization. It seems to have reached the long drawn out plateau phase in most of the states in this sub-continent.

\section{$\underline{\text { Acknowledgements }}$}

I am grateful to the Norwegian Save the Children Organization and the Sasakawa Memorial Health Foundation for inviting me to participate in this International Symposium on the Epidemiology of leprosy at Geilo in Norway.

\section{References}

1 Dharmendra. The Present Distribution of Leprosy. Bombay: Kothari Medical Publishing House, Leprosy, 1978, Vol. I, pp 2227.

2 Shamrao A. Leprosy Surveys in Hyderabad, Deccan. Lepr India, $1944,16,123$.

3 Mathur NK, Kanwar AJ, Kalla G, Ujwal JS. Leprosy in Jodhpur, Rajasthan: Clinical and Epidemiological Study of Leprosy. Lepr India, 1978, 50, 204.

4 Dharmendra. Editorial: Some Observations on the Prevalence of Leprosy in Punjab and Rajasthan. Lepr India, 1981, 53, 334.

5 Wade HW, Ledowsky $V$. The Leprosy epidemic at Nauru; a review 
with data on the status since 1937. Int J Lepr, 1952, 20, 1.

6 Leiker DL. Epidemiological and immunological surveys in Netherlands New Guinea. Lepr R v, 1960, 31, 241.

7 Balraj V, Jesudasan K, Chacko CJG, Christian M, Taylor PM, Fritschi EP, Job CK. Prevalence of Secondary Dapsone Resistance in Gudiyatham Taluk, the Leprosy Control area of the Schieffelin Leprosy Research and Training Centre, Karigiri. Preliminary report. Int J Lepr, 1980, 48, 397.

Fig. 1. Distribution of leprosy in India.

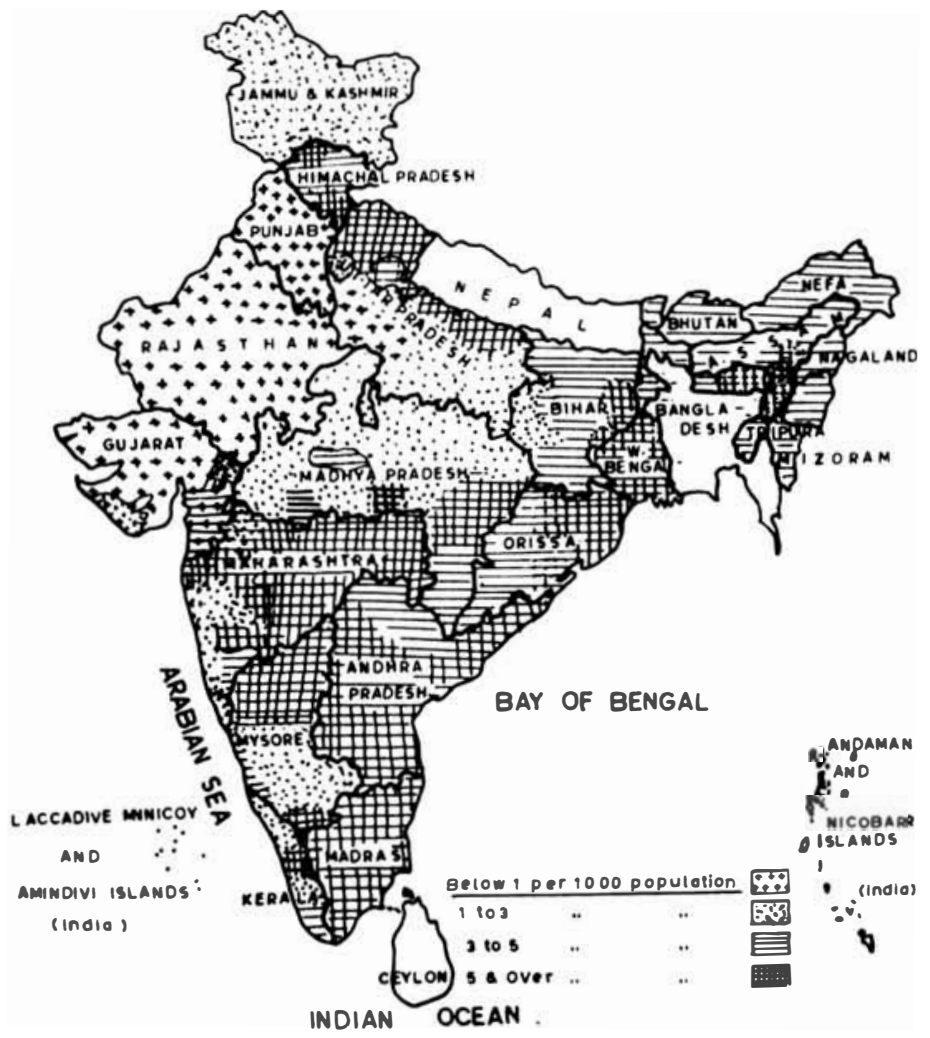

